\title{
Dietary Macronutrient Composition in Relation to Circulating HDL and Non-HDL Cholesterol: A Federated Individual-Level Analysis of Cross-Sectional Data from Adolescents and Adults in 8 European Studies
}

\author{
Mariona Pinart, ${ }^{1}$ Stephanie Jeran, ${ }^{1}$ Heiner Boeing, ${ }^{2}$ Marta Stelmach-Mardas, ${ }^{2,3}$ Marie Standl, ${ }^{4}$ \\ Holger Schulz, ${ }^{4}$ Carla Harris, ${ }^{4,5}$ Andrea von Berg, ${ }^{6}$ Gunda Herberth, ${ }^{7}$ Sybille Koletzko, ${ }^{8,9}$ \\ Jakob Linseisen, ${ }^{10,11}$ Taylor A Breuninger, ${ }^{10}$ Ute Nöthlings, ${ }^{12}$ Janett Barbaresko, ${ }^{12,13}$ Stefan Benda, ${ }^{12}$ \\ Carl Lachat, ${ }^{14}$ Chen Yang, ${ }^{14}$ Paolo Gasparini, ${ }^{15,16}$ Antonietta Robino, ${ }^{16}$ Gemma Rojo-Martínez, ${ }^{17,18}$ \\ Luís Castaño, ${ }^{19}$ Michèle Guillaume ${ }^{20}$ Anne-Françoise Donneau, ${ }^{20}$ Axelle Hoge ${ }^{20}$ Nicolas Gillain, ${ }^{20}$ \\ Demetris Avraam, ${ }^{21}$ Paul R Burton, ${ }^{21}$ Jildau Bouwman, ${ }^{22}$ Tobias Pischon, $, 23,24,25$ and Katharina Nimptsch ${ }^{1}$
}

\begin{abstract}
${ }^{1}$ Molecular Epidemiology Research Group, Max Delbrück Center for Molecular Medicine in the Helmholtz Association (MDC), Berlin, Germany; ${ }^{2}$ Department of Epidemiology, German Institute of Human Nutrition Potsdam-Rehbrücke, Nuthetal, Germany; ${ }^{3}$ Department of Treatment of Obesity, Metabolic Disorders and Clinical Dietetics, Poznan University of Medical Sciences, Poznan, Poland; ${ }^{4}$ Helmholtz Centre Munich-German Research Center for Environmental Health, Institute of Epidemiology, Neuherberg/Munich, Germany; ${ }^{5}$ Division of Metabolic and Nutritional Medicine, LMU - Ludwig Maximilian University Munich, Dr. von Hauner Children’s Hospital, LMU University Hospitals, Munich, Germany; ${ }^{6}$ Department of Pediatrics, Research Institute, Marien-Hospital Wesel, Wesel, Germany; ${ }^{7}$ Department of Environmental Immunology, Helmholtz Centre for Environmental Research-Zentrum für Umweltforschung (UFZ), Leipzig, Germany; ${ }^{8}$ Department of Pediatrics, Dr. von Hauner Children's Hospital, LMU - Ludwig Maximilian University Hospital, University of Munich, Munich, Germany; ${ }^{9}$ Department of Pediatrics, Gastroenterology and Nutrition, School of Medicine Collegium Medicum University of Warmia and Mazury, Olsztyn, Poland; ${ }^{10}$ Helmholtz Centre Munich, Clinical Epidemiology, Neuherberg/Munich, Germany; ${ }^{11}$ Ludwig Maximilians University (LMU) Munich, Medical Faculty, Chair of Epidemiology at University Center for Health Sciences at the Klinikum Augsburg (UNIKA-T), Ausburg, Germany; ${ }^{12}$ Department of Nutrition and Food Sciences, University of Bonn, Bonn, Germany; ${ }^{13}$ Institute for Biometrics and Epidemiology, German Diabetes Center, Leibniz Center for Diabetes Research at Heinrich Heine University Düsseldorf, Düsseldorf, Germany; ${ }^{14}$ Department of Food Technology, Safety and Health, Ghent University, Ghent, Belgium; ${ }^{15}$ Department of Medical Sciences, University of Trieste, Trieste, Italy; ${ }^{16}$ Institute for Maternal and Child Health-Mother and Child Referral Hospital and Research Institute (IRCCS) "Burlo Garofolo," Trieste, Italy; ${ }^{17}$ Spanish Biomedical Research Center in Diabetes and Associated Metabolic Disorders (CIBERDEM), Madrid, Spain; ${ }^{18}$ Clinical Management Unit (CMU) Endocrinology and Nutrition, Regional University Hospital of Malaga, Institute of Biomedical Research in Malaga (IBIMA), Málaga, Spain; ${ }^{19}$ Spanish Biomedical Research Center in Diabetes and Associated Metabolic Disorders (CIBERDEM), Rare Diseases Networking Biomedical Research Centre (CIBERER), BioCruces-University Hospital Cruces-The University of the Basque Country (Basque: Euskal Herriko Unibertsitatea/Spanish: Universidad del País Vasco [UPV/EHU]), Barakaldo, Spain; ${ }^{20}$ Department of Public Health, University of Liège, Liège, Belgium;

${ }^{21}$ Population Health Sciences Institute, Newcastle University, Newcastle upon Tyne, United Kingdom; ${ }^{22}$ Research group Microbiology and Systems Biology, Netherlands Organization for Applied Scientific Research, Zeist, The Netherlands; ${ }^{23}$ Charité University Medicine Berlin, Berlin, Germany; ${ }^{24}$ Max Delbrück Center for Molecular Medicine (MDC)/Berlin Institute of Health (BIH) Biobank, Berlin, Germany; and ${ }^{25}$ German Centre for Cardiovascular Research (DZHK), Berlin, Germany
\end{abstract}

\section{ABSTRACT}

Background: Associations between increased dietary fat and decreased carbohydrate intake with circulating HDL and non-HDL cholesterol have not been conclusively determined.

Objective: We assessed these relations in 8 European observational human studies participating in the European Nutritional Phenotype Assessment and Data Sharing Initiative (ENPADASI) using harmonized data.

Methods: Dietary macronutrient intake was recorded using study-specific dietary assessment tools. Main outcome measures were lipoprotein cholesterol concentrations: HDL cholesterol (mg/dL) and non-HDL cholesterol (mg/dL). A cross-sectional analysis on 5919 participants (54\% female) aged 13-80 y was undertaken using the statistical platform DataSHIELD that allows remote/federated nondisclosive analysis of individual-level data. Generalized linear models (GLM) were fitted to assess associations between replacing $5 \%$ of energy from carbohydrates with equivalent energy from total fats, SFAs, MUFAs, or PUFAs with circulating HDL cholesterol and non-HDL cholesterol. GLM were adjusted for study source, age, sex, smoking status, alcohol intake and BMI.

Results: The replacement of $5 \%$ of energy from carbohydrates with total fats or MUFAs was statistically significantly associated with $0.67 \mathrm{mg} / \mathrm{dL}$ (95\% Cl: $0.40,0.94)$ or $0.99 \mathrm{mg} / \mathrm{dL}(95 \% \mathrm{Cl}: 0.37,1.60)$ higher $\mathrm{HDL}$ cholesterol, respectively, but not with non-HDL cholesterol concentrations. The replacement of $5 \%$ of energy from carbohydrates with SFAs or 
PUFAs was not associated with HDL cholesterol, but SFAs were statistically significantly associated with $1.94 \mathrm{mg} / \mathrm{dL}$ (95\% Cl: 0.08, 3.79) higher non-HDL cholesterol, and PUFAs with $-3.91 \mathrm{mg} / \mathrm{dL}$ (95\% Cl: $-6.98,-0.84)$ lower non-HDL cholesterol concentrations. A statistically significant interaction by sex for the association of replacing carbohydrates with MUFAs and non-HDL cholesterol was observed, showing a statistically significant inverse association in males and no statistically significant association in females. We observed no statistically significant interaction by age.

Conclusions: The replacement of dietary carbohydrates with fats had favorable effects on lipoprotein cholesterol concentrations in European adolescents and adults when fats were consumed as MUFAs or PUFAs but not as SFAs. $J$ Nutr 2021;00:1-13.

Keywords: energy density models, substitution, blood lipids, dietary intake, fatty acids, carbohydrates, adults, adolescents, data sharing, data integration

\section{Introduction}

Cardiovascular diseases (CVDs) are the most common cause of death worldwide, causing over 4 million deaths $(45 \%$ of all deaths) each year across Europe (1). Key risk factors accounting for $\sim 50 \%$ of CVDs are alterations in the lipoprotein metabolism such as high concentrations of total (TC) and LDL cholesterol, and low concentrations of HDL cholesterol (2). Non-HDL cholesterol reflects the full burden of cholesterol carried by all potentially atherogenic particles, including LDL cholesterol, intermediate density lipoproteins, VLDLs, and remnant lipoproteins (3). European guidelines recommend

The European Nutritional Phenotype Assessment and Data Sharing Initiative (ENPADASI) and its infrastructure are part of the Joint Programming Initiative "A Healthy Diet for a Healthy Life" (JPI-HDHL) and is funded by national funding agencies in 9 European countries. This work is financially supported by the German Ministry of Food and Agriculture (BMEL) through the Federal Office for Agriculture and Food (BLE), grant number 2814ERA01F, and the German Ministry of Education and Research (BMBF), grant number 2814ERA03F. The GINIplus and LISA studies were mainly supported by Helmholtz Centre Munich (former GSF), Helmholtz Centre for Environmental Research - UFZ, Leipzig, Research Institute at Marien-Hospital Wesel, LMU Munich, TU Munich, and also from IUF - Leibniz Research-Institute for Environmental Medicine at the University of Düsseldorf, and a grant from the Federal Ministry for Environment (IUF Düsseldorf, FKZ 20462296); and the Federal Ministry for Education, Science, Research and Technology, Helmholtz Centre Munich (former GSF), Research Institute at Marien-Hospital Wesel, IUF - Leibniz Research-Institute for Environmental Medicine at the University of Düsseldorf, the Federal Ministry for Environment (IUF Düsseldorf, FKZ 20462296), and the Commission of the European Communities, the 7th Framework Program: MeDALL project. The GINIplus study was also supported by LMU Munich, TU Munich, and the companies Mead Johnson and Nestlé. The LISA study was also supported by the Helmholtz Centre for Environmental Research - UFZ, Leipzig, Pediatric Practice, Bad Honnef. CL and CY were supported by FWO Research Foundation Flanders, grant number G0D4815N. CY is funded by a scholarship from the Chinese Scholarship Council.

Author disclosures: The authors report no conflicts of interest.

Supplemental Tables 1 to 5 and Supplemental Figures 1 to 4 are available from the "Supplementary data" link in the online posting of the article and from the same link in the online table of contents at https://academic.oup.com/jn/.

Address correspondence to KN (e-mail: Katharina.Nimptsch@mdc-berlin.de).

Abbreviations used: AC, analysis computer; BVS II, Bavarian Food Consumption Survey II; CVD, cardiovascular disease; DASH-IN, Data Sharing Initiative for Nutrition; DC, data computer; DONALD Study, DOrtmund Nutritional and Anthropometric Longitudinally Designed Study; ENPADASI, European Nutritional Phenotype Assessment and Data Sharing Initiative; EPIC, European Prospective Investigation into Cancer and Nutrition-Potsdam substudy; FAIR, Findable, Accessible, Interoperable, and Re-usable; GINIplus, German Infant Study on the Influence of Nutrition Intervention plus environmental and genetic influences on allergy development; GLM, generalized linear models; INGI-FVG, Italian Network of Genetic Isolates - Friuli Venezia Giulia; IPD, individual person data; LISA, Influence of Life-style related factors on the development of the Immune System and Allergies in East and West Germany; NESCaV, Nutrition, Environment and Cardiovascular Health; SLMA, study-level meta-analysis; TC, total cholesterol. a reduction of $\mathrm{TC}$ and $\mathrm{LDL}$ cholesterol concentrations as primary targets in therapeutic interventions for both primary and secondary prevention of CVD (4). However, several meta-analyses found that non-HDL cholesterol correlated more closely with cardiovascular risk than LDL cholesterol, and non-HDL cholesterol has therefore recently emerged as a new target for the prevention of cardiovascular events (5). Non-HDL cholesterol is considered a better parameter because it includes remnant cholesterol and is independent of triglyceride variability (6). In addition, indirect measurement of LDL cholesterol using the traditional Friedewald equation, as is common in clinical practice, tends to underestimate LDL cholesterol concentrations (7), particularly in those with lower LDL cholesterol $(<70 \mathrm{mg} / \mathrm{dL})$ and higher triglyceride concentrations ( $\geq 150 \mathrm{mg} / \mathrm{dL})(8)$.

It has been estimated that diet-related risks accounted for 2.1 million deaths from CVDs (95\% uncertainty interval [UI], 1.7-2.5 million) in the WHO European Region within $1 \mathrm{y}$ in 2016 , reflecting $22.4 \%$ of all deaths and $49.2 \%$ of CVD deaths (9). Modifying the macronutrient composition of habitual diet can have beneficial effects on lowering CVD risk via lipid risk factors (10). For example, diets low in SFAs are recommended for the prevention of CVD by lowering LDL cholesterol concentrations (11), whereas diets rich in carbohydrates have shown detrimental effects on blood lipids by reducing HDL cholesterol concentrations and raising fasting concentrations of triglycerides $(12,13)$. There is a need to better understand the effects of replacing carbohydrates with different types of fats in relation to lipoprotein profiles, especially in relation to non-HDL cholesterol. In randomized dietary intervention trials, substituting carbohydrates with unsaturated fatty acids, predominantly MUFAs, increased HDL cholesterol and reduced LDL cholesterol concentrations $(10,14,15)$. Moreover, the replacement of carbohydrates with PUFAs increased HDL cholesterol and decreased TC and LDL cholesterol concentrations, whereas substituting carbohydrates with SFAs increased TC, HDL cholesterol, and LDL cholesterol $(15,16)$. However, there is little evidence on modified macronutrient composition and non-HDL cholesterol. In addition, randomized trials often used strictly controlled dietary interventions $(14,15)$, were conducted in special study collectives (prehypertension or Stage 1 hypertension (14), overweight or obese (17)), had narrow ageranges and/or small sample size $(14,15)$ precluding sex- or agespecific analyses and inferences to the habitual diet in the general population.

Therefore, in the present study we investigated the association of the isocaloric replacement of carbohydrates with total fat or different types of fat with blood lipoproteins 
(HDL cholesterol, non-HDL cholesterol, and the ratio of HDL cholesterol to TC [HDL cholesterol/TC]) by sex and age in 8 European observational studies participating in the European Nutritional Phenotype Assessment and Data Sharing Initiative (ENPADASI) project (18) covering a broad age range. Harmonized datasets were analyzed in a federated way in the ENPADASI Data Sharing Initiative for Nutrition (DASH-IN) (www.enpadasi.eu) implementation of DataSHIELD $(19,20)$, a statistical platform that allows remote/federated nondisclosive analysis of individual-level data from multiple studies without physically pooling or sharing them.

\section{Methods}

\section{Study population}

The observational studies included in the present study were identified in the ENPADASI initiative where a total of 26 observational studies were identified (18). Briefly, a consortium was built to identify studies from consortium partners with a wealth of data and metadata, particularly on dietary intake and traditional and omics biomarkers, as well as to develop the DASH-IN infrastructure to facilitate data exchange and data interpretation in order to increase the robustness of results from future joint (pooled or federated) data analysis in nutritional epidemiology (www.enpadasi.eu).

We planned to include studies with data on dietary macronutrient intake and blood lipids such as TC and HDL cholesterol. From the 26 observational studies identified in ENPADASI, 10 studies fulfilled the inclusion criteria and were therefore preselected. An invitation to participate in the present study was sent to the principal investigators of the preselected studies. Those who accepted the invitation (8 out of 10) were included in our analyses. The studies included in this federated analysis are described in Table 1 . Briefly, we included 8 studies comprising a total number of 12,983 participants from the general population aged 13-80 y: 1 study from Belgium (Nutrition, Environment and Cardiovascular Health [NESCaV]) (21), 5 from Germany (Bavarian Food Consumption Survey II [BVS II]) (22), ActivE (23), EPIC (European Prospective Investigation into Cancer and Nutrition)Potsdam substudy (24), DOrtmund Nutritional and Anthropometric Longitudinally Designed Study (DONALD) (25), German Infant Study on the Influence of Nutrition Intervention plus environmental and genetic influences on allergy development (GINIplus), and Influence of Life-style related factors on the development of the Immune System and Allergies in East and West Germany (LISA) (26), 1 from Italy (Italian Network of Genetic Isolates - Friuli Venezia Giulia [INGIFVG]) (27), and 1 from Spain (Pizarra) (28). Three studies were crosssectional and 5 were longitudinal by design, in which case data at baseline or at a single follow-up (GINIplus and LISA) were used for the cross-sectional analysis. All of the participants of the studies provided informed consent, and studies were approved by their local ethics committee (18).

\section{Data assessments}

\section{Exposure variables.}

Dietary macronutrient intake (fat, carbohydrates, and protein intake) was assessed using multiple 24-h dietary recalls (BVS-II [22], EPIC substudy [24], and Pizarra [28]), self-completed, paper- or computerbased semiquantitative FFQs (NESCaV [21], GINIplus and LISA [29]), self-completed and paper-based food records (ActivE [23] and DONALD [25]), or other methods, e.g. dietary history interview (INGIFVG) (27) (Table 1). Dietary assessment instruments were validated and validation results have been published elsewhere (30-35), with the exception of ActivE, in which the food record was validated against doubly labeled water (for total energy expenditure/total energy intake, unpublished data). From the respective dietary assessment instrument, energy intake $(\mathrm{kcal} / \mathrm{d})$ and macronutrient intakes (total fat, SFA, MUFA, PUFA, protein, and carbohydrate, all in $\mathrm{g} / \mathrm{d}$ ) were calculated using country-specific food composition tables.

\section{Outcome variables.}

Blood lipids (HDL cholesterol and TC) were measured in plasma samples in the EPIC substudy and in serum in all other studies (Table 1). Non-HDL cholesterol and the ratio of HDL cholesterol to TC (HDL cholesterol/TC) were calculated (see data harmonization process).

\section{Covariables.}

Covariables such as age, sex, smoking status, and alcohol consumption, were obtained from study-specific questionnaires. Height $(\mathrm{cm})$ and weight $(\mathrm{kg})$ were measured in each study (Supplemental Table 1).

\section{Data harmonization process}

For the purpose of data harmonization, a catalogue with the exact name of the variables, a description of each variable, the units, an example of their value as well as a column for comments was prepared following the FAIR (Findable, Accessible, Interoperable, and Re-usable) principles (36). The harmonized datasets were uploaded by the study partners on local servers together with their data dictionary. The following harmonized variables were requested: age $(\mathrm{y})$, sex, height $(\mathrm{cm})$, weight $(\mathrm{kg})$, smoking status (never, former, and current), HDL cholesterol (mg/dL), LDL cholesterol (mg/dL), TC (mg/dL), alcohol consumption $(\mathrm{g} / \mathrm{d})$, total energy intake $(\mathrm{kcal} / \mathrm{d})$, dietary intakes of carbohydrates $(\mathrm{g} / \mathrm{d})$, protein $(\mathrm{g} / \mathrm{d})$, total fat $(\mathrm{g} / \mathrm{d})$, SFA $(\mathrm{g} / \mathrm{d})$, MUFA $(\mathrm{g} / \mathrm{d})$, and PUFA $(\mathrm{g} / \mathrm{d})$ (Supplemental Table 1).

The following variables were computed after the harmonization process: the percentage of energy available from carbohydrates, proteins, and fats were obtained by multiplying the number of daily grams of carbohydrate, protein, and fat (including SFA, MUFA, and PUFA) by their energy content per gram (4.0, 4.0, and $9.0 \mathrm{kcal}$, respectively), and divided by the total energy intake ( $\mathrm{kcal} / \mathrm{d})$. NonHDL cholesterol was calculated as TC minus HDL cholesterol. The HDL cholesterol/TC ratio was calculated as the percentage of HDL cholesterol with respect to TC (2). Smoking status was recoded into 2 categories (never/former and current), a categorical variable "nondrinkers and drinkers" (nondrinkers if alcohol consumption $<0.3 \mathrm{~g} / \mathrm{d})$ was created, and BMI $\left(\mathrm{kg} / \mathrm{m}^{2}\right)$ was calculated from weight $(\mathrm{kg})$ and height (in meters).

\section{Statistical analysis}

Across the 8 studies (total $n=12,983$ participants), we only included participants with complete data on HDL cholesterol and total energy intake in the analyses (total $n=5960,45.9 \%$ ). We further excluded participants with missing values in the outcome variable non-HDL cholesterol $(n=1$ in GINIplus/LISA, $n=1$ in NESCaV) or in the macronutrient intake variables $(n=38$ in NESCaV, $n=1$ for type of fats in Pizarra), resulting in a total of 5919 individuals. Statistical analyses were performed using the DataSHIELD tool, which allowed remote federated analysis of harmonized datasets across the studies without physically sharing their individual-level data (19). Briefly, individual participant data from contributing studies were held securely on servers at each study location (data computers [DC]) (19). A computer within the network (analysis computer $[\mathrm{AC}]$ ) sent analytical commands that requested each local server (DC) to undertake an analysis locally and to return nonidentifiable summary statistics (e.g. estimates and CIs) for each individual study. Participants' characteristics were described by means (SD) for (approximately) normally distributed and medians (2575 th percentile) for skewed distributed continuous variables, or counts $(\%)$ for categorical variables. As statistical normality tests were not available in DataSHIELD, normality was assessed by visual inspection of histograms. Generalized linear regression models (GLM) were carried out to determine the cross-sectional associations between macronutrient composition (independent variables) and HDL cholesterol and nonHDL cholesterol concentrations, as well as the HDL cholesterol/TC ratio (dependent variables). DataSHIELD offers 2 complementary approaches: 1) a full-likelihood-based individual person data (IPD) methodology (also known as the "virtual IPD analysis") where data are effectively analyzed on an individual person basis, but without physically moving them from their usual trusted repository. This 


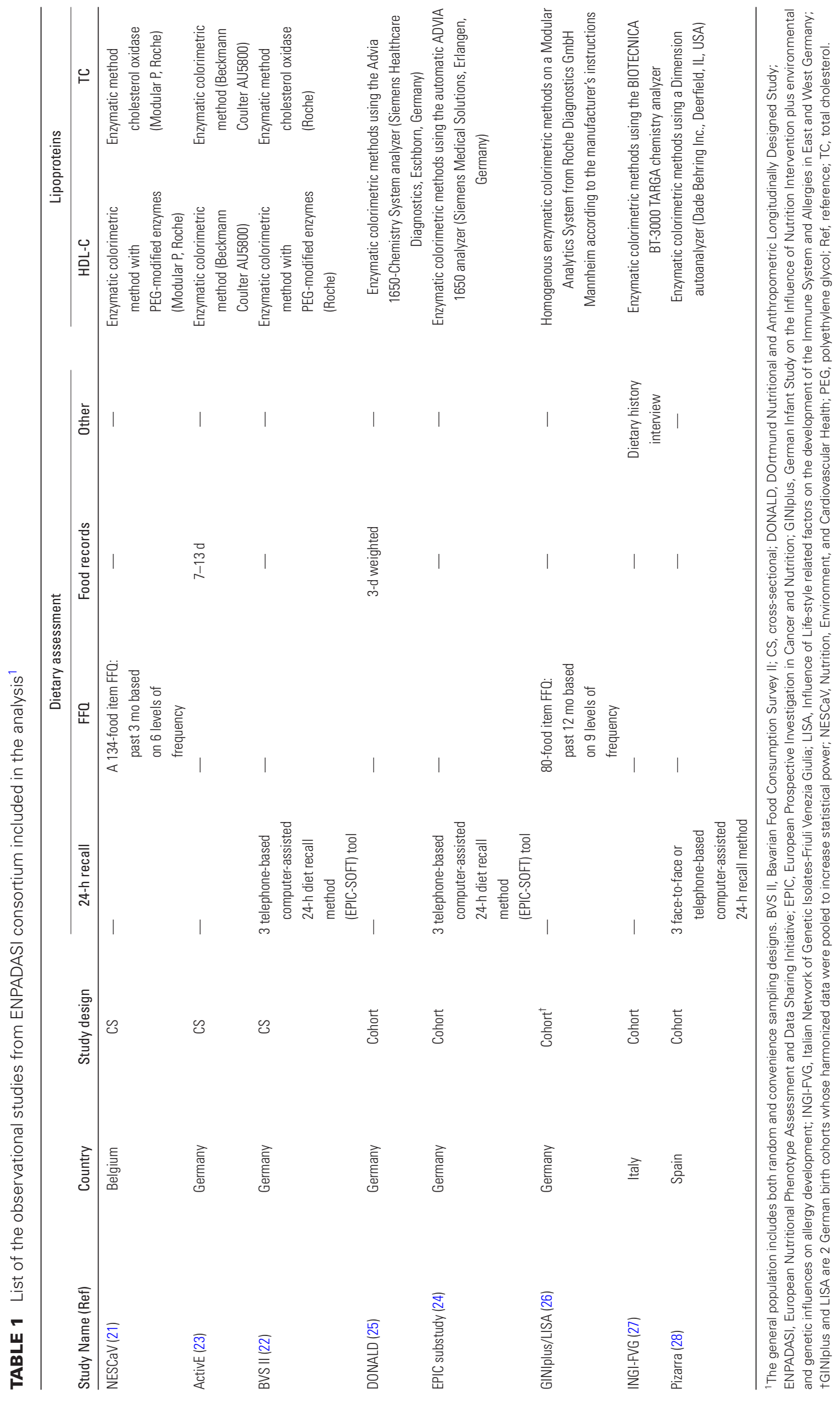

4 Pinart et al. 
approach generates the same results as if the data from all sources were physically transferred to a central warehouse and analyzed jointly (19). 2) A study level meta-analysis (SLMA), sometimes called federated meta-analysis, where the analysis is undertaken in each study separately and then all the resultant estimates and SEs are combined using conventional SLMA methods.

We conducted virtual IPD GLM as a primary analysis approach. In order to compare the results, we conducted SLMA GLM as secondary analysis. For the virtual IPD analysis, each GLM was fitted in a federated manner using the iterative reweighted least squares process. At each iteration, DataSHIELD transmitted the score vectors and information matrices - which are fully efficient nondisclosive summary statistics from each study to the AC (37). For the SLMA, GLMs were fitted to completion in each study and DataSHIELD then transmitted the studyspecific effect estimates and SEs - again, nondisclosive - to the AC (19), where they were combined across studies using random-effects meta-analysis under restricted maximum likelihood (REML) using $\mathrm{R}$ "metafor" packages v. 3.3.2. Heterogeneity was tested using $\mathrm{chi}^{2}$ and $I^{2}$ statistics (38). Significance was set as $P<0.05$ for the chi ${ }^{2}$ test. Careful interpretation of the value of $I^{2}$ depends on the magnitude and direction of effects, and strength of evidence for heterogeneity. $I^{2}$ values of $0-40 \%, 30-60 \%, 50-90 \%$, and $75-100 \%$ were considered to indicate low, moderate, substantial, and considerable heterogeneity, respectively.

Multivariable nutrient density models were used to estimate the association of isocaloric replacement (as 5\% of energy) of carbohydrate with total fats or with different types of fats namely SFA, MUFA, and PUFA. The $5 \%$ increment was chosen to be comparable to previous investigations on macronutrient composition (12). Percentages of energy from total fat or different types of fats (SFA, MUFA, and PUFA) were included as exposure variables along with percentage of energy from proteins and total energy intake as covariates (39). The coefficients of these multivariable nutrient density models indicate differences in blood lipid concentrations associated with replacing $5 \%$ of energy intake from carbohydrates with equivalent energetic amounts of dietary fats.

The adjustment variables were chosen a priori and were comparable to the set of covariates used in similar analyses on macronutrient intake and lipoprotein profiles described elsewhere $(40,41)$. Missing values for smoking status were found in BVS II $(n=1)$, INGI-FVG $(n=14)$, DONALD $(n=50)$, GINIplus and LISA $(n=69)$, and NESCaV $(n=2)$ studies. In addition, missing values for BMI were found in INGI-FVG $(n=62)$, GINIplus and LISA $(n=11)$, and $\operatorname{NESCaV}(n=1)$ studies. Missing data were handled separately for each study by simple imputations. Briefly, missing data for smoking status were handled by imputing the missing values with the value for the most frequent category among the total study population since no sex-specific differences were observed, and missing data for BMI was handled by imputing missing values with sex-specific median values. Regression models were computed separately for each blood lipid and macronutrient association. We constructed 2 models with different adjustments for covariates. Model 1 included percentage of energy from proteins (continuously), total energy intake ( $\mathrm{kcal} / \mathrm{d})$, alcohol consumption (nondrinker [yes/no] and continuous intake in $\mathrm{g} / \mathrm{d}$ ), and study source. Model 2 was further adjusted for age (y), sex, smoking status (never/former, current), and BMI. Analyses were conducted in males and females combined as well as stratified by sex.

We assessed linear regression assumptions through histograms and scatter plots of regression residuals and fitted values using privacy-preserving variants of standard regression diagnostics recently implemented in DataSHIELD (42). We also investigated the potential for collinearity between model terms. In addition, in order to investigate whether potentially nonlinear associations exist we added quadratic terms of percentage of energy from total fat, SFA, MUFA, and PUFA separately to the models along with the linear terms and checked their significance using the Wald test.

In order to examine whether observations were consistent across different age groups, we also conducted stratified analyses by age $(\leq 30$ [ $n=6$ studies], 31-40 $[n=4], 41-50[n=4], 51-60[n=5]$ and $>60 y$ $[n=5])$. All participants from GINIplus and LISA fell into the age category $\leq 30 \mathrm{y}$. Participants from the DONALD study fell into the first 2 categories ( $\leq 30$ and $31-40$ y). However, aggregated results for the age category of $31-40$ y were not returned by DataSHIELD because they were disclosive. A contingency table is considered as providing a potential disclosure risk, if any of its cells have less counts than a prespecified threshold (43). To address this problem under DataSHIELD, each DC tested any contingency table that was created and only returned a full table to the $\mathrm{AC}$ if all cells were empty or contained $\geq 5$ observations. The EPIC substudy had participants in the last 3 age categories $(41-50,51-60$, and $>60 \mathrm{y})$; however, aggregated results for the age category of $41-50$ y could not be used since they were potentially disclosive. ActivE was removed from the age-stratified analyses due to disclosive results in all age categories. Statistical interactions were investigated in GLM virtual IPD analyses by including a crossproduct term for macronutrient intake, e.g. total fats or type of fats (continuous), and the stratification variable (age [continuous] or sex), along with the main effect terms of each in the model with each blood lipid as the dependent variable. All studies were included in the interaction analysis. The $P$ value for interaction was determined by a Wald test.

Results were considered statistically significant at a level of $P<0.05$ throughout. All statistical analyses were performed in DataSHIELD version 5.0.0 (19).

\section{Results}

The number of included participants with complete data from the 8 studies ranged between 50 and 2126, totaling 5919 participants' data available for a combined analysis, of which 3197 (54\%) were female (Table 2). The percentage of female sex ranged between $49 \%$ (EPIC substudy) to $65 \%$ (Pizarra). Mean HDL cholesterol concentrations ranged between $46.6 \mathrm{mg} / \mathrm{dL}$ (BVS II) and $67.1 \mathrm{mg} / \mathrm{dL}$ (Pizarra). Mean non-HDL cholesterol concentrations ranged between $108 \mathrm{mg} / \mathrm{dL}$ (DONALD study) and $184 \mathrm{mg} / \mathrm{dL}$ (Pizarra). Median intakes of total fats ranged from $30.6 \%$ (GINIplus and LISA) to $42.6 \%$ (Pizarra), SFA ranged from $9.13 \%$ (INGI-FVG) to $16.7 \%$ (EPIC substudy), MUFA ranged from $10.9 \%$ (GINIplus and LISA) to $18.9 \%$ (Pizarra), and PUFA ranged from $2.98 \%$ (INGI-FVG) to $6.63 \%$ (EPIC substudy).

We assessed linear regression assumptions and no violations were observed. Furthermore, little or no multicollinearity was observed in the data (data not shown). The associations between (5\% of energy) replacement of carbohydrates with total and different types of fats and HDL cholesterol and non-HDL cholesterol are depicted in Table 3 and stratified by sex in Table 4 . In the fully adjusted model including sex, age, smoking status, and BMI (model 2) replacing 5\% of energy from carbohydrates with the same amount of energy from total fat was statistically significantly associated with $0.67 \mathrm{mg} / \mathrm{dL}$ (95\% CI: 0.40, 0.94; $P<0.0001$ ) higher HDL cholesterol. No statistically significant associations between the replacement of carbohydrates with total fats and non-HDL cholesterol concentrations were observed $(-0.37 \mathrm{mg} / \mathrm{dL}, 95 \% \mathrm{CI}:-1.10$, $0.36 ; P=0.32$ ) (Table 3). Although the isocaloric replacement of carbohydrates with SFAs was not associated with higher HDL cholesterol, it was statistically significantly associated with $1.94 \mathrm{mg} / \mathrm{dL}$ (95\% CI: 0.08, 3.79; $P=0.04$ ) higher non-HDL cholesterol in model 2. The higher intake of MUFAs in place of carbohydrates was statistically significantly associated with $0.99 \mathrm{mg} / \mathrm{dL}$ (95\% CI: 0.37, 1.60; $P=0.002$ ) higher HDL cholesterol, but no associations were found with non-HDL cholesterol concentrations. A higher PUFA intake in place of carbohydrates yielded no statistically significant associations 


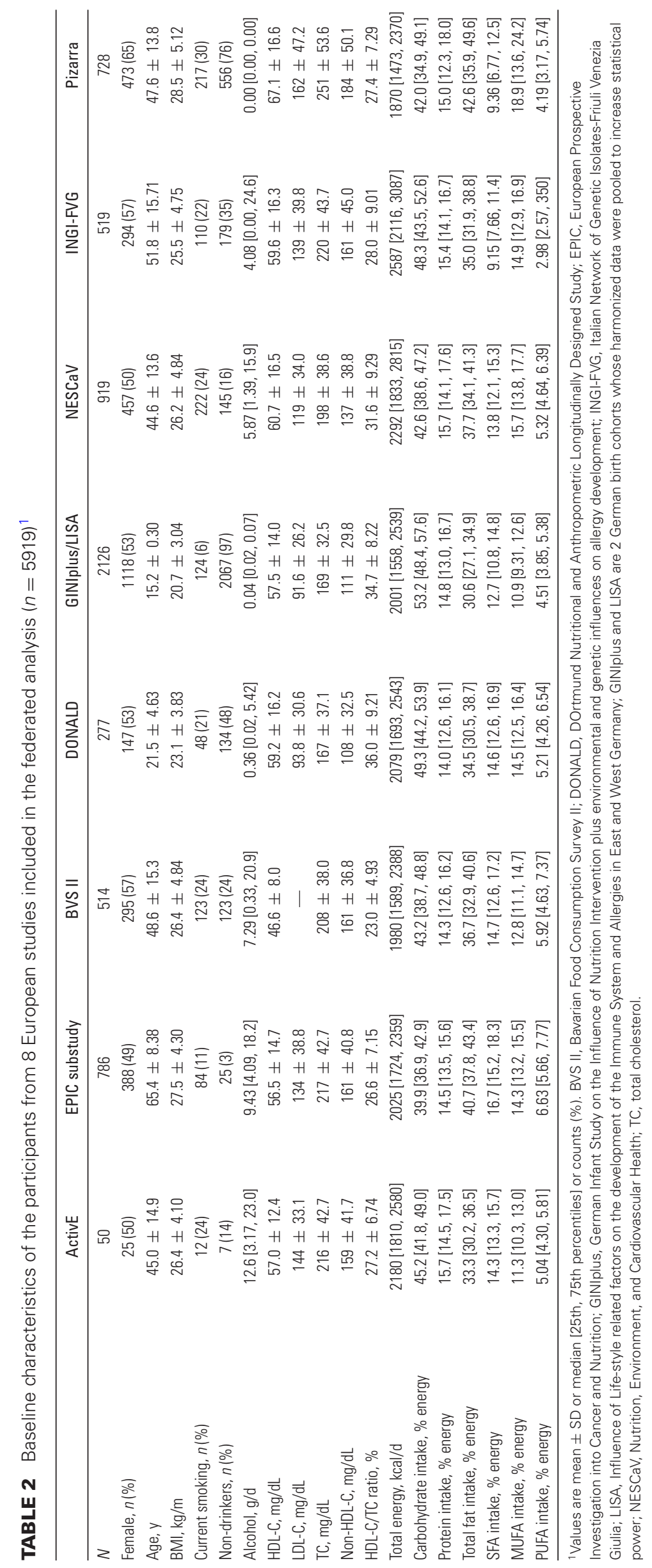


TABLE 3 Associations between replacement of $5 \%$ of energy from carbohydrates with total fats or types of fats and HDL cholesterol and non-HDL cholesterol among adolescents and adults from 8 European studies $(n=5919)^{1}$

\begin{tabular}{|c|c|c|c|c|}
\hline Type of fat & $\begin{array}{c}\text { HDL-C } \\
\beta(95 \% \mathrm{Cl})\end{array}$ & $P$ value & $\begin{array}{c}\text { Non-HDL-C } \\
\beta(95 \% \mathrm{CI})\end{array}$ & $P$ value \\
\hline \multicolumn{5}{|l|}{ Total fats } \\
\hline Model 1 & $0.81(0.52,1.09)^{*}$ & $<0.0001$ & $-0.12(-0.86,0.63)$ & 0.76 \\
\hline Model 2 & $0.67(0.40,0.94)^{*}$ & $<0.0001$ & $-0.37(-1.10,0.36)$ & 0.32 \\
\hline \multicolumn{5}{|l|}{ SFA } \\
\hline Model 1 & $1.37(0.64,2.10)^{*}$ & 0.0002 & $2.20(0.31,4.09)^{*}$ & 0.02 \\
\hline Model 2 & $0.55(-0.13,1.23)$ & 0.11 & $1.94(0.08,3.79)^{*}$ & 0.04 \\
\hline \multicolumn{5}{|l|}{ MUFA } \\
\hline Model 1 & $0.46(-0.20,1.12)$ & 0.17 & $-0.77(-2.47,0.93)$ & 0.37 \\
\hline Model 2 & $0.99(0.37,1.60)^{*}$ & 0.002 & $-0.85(-2.51,0.81)$ & 0.32 \\
\hline \multicolumn{5}{|l|}{ PUFA } \\
\hline Model 1 & $0.12(-1.09,1.33)$ & 0.85 & $-2.80(-5.94,0.34)$ & 0.08 \\
\hline Model 2 & $-0.30(-1.43,0.83)$ & 0.61 & $-3.91(-6.98,-0.84)^{*}$ & 0.01 \\
\hline
\end{tabular}

${ }^{1}$ Data are $\beta$-coefficients, upper and lower $95 \% \mathrm{Cls}$ for all participants. Values of HDL cholesterol and non-HDL cholesterol are expressed in $\mathrm{mg} / \mathrm{dL}$ and total fat, SFA, MUFA, and PUFA intakes as $5 \%$ energy. General linear regression models were used. Model 1 was adjusted for alcohol (yes, no, and continuously in $\mathrm{g} / \mathrm{d}$ ), protein intake, $5 \%$ energy (continuously), total energy intake ( $\mathrm{kcal} / \mathrm{d})$, and study source (EPIC substudy, ActivE, BVS II, DONALD, Pizarra, NESCaV, GINIplus and LISA, INGI-FVG); and model 2 was additionally adjusted for age (y), sex, smoking status (never/former, current), and BMI $\left(\mathrm{kg} / \mathrm{m}^{2}\right)$. ${ }^{*} P<0.05$. BVS II, Bavarian Food Consumption Survey II; DONALD, DOrtmund Nutritional and Anthropometric Longitudinally Designed Study; EPIC, European Prospective Investigation into Cancer and Nutrition; GINIplus, German Infant Study on the Influence of Nutrition Intervention plus environmental and genetic influences on allergy development; INGI-FVG, Italian Network of Genetic Isolates-Friuli Venezia Giulia; LISA, Influence of Life-style related factors on the development of the Immune System and Allergies in East and West Germany; GINIplus and LISA are 2 German birth cohorts whose harmonized data were pooled to increase statistical power; NESCaV, Nutrition, Environment, and Cardiovascular Health.

with HDL cholesterol, but a statistically significant association with lower $(-3.91 \mathrm{mg} / \mathrm{dL}, 95 \% \mathrm{CI}:-6.98,-0.84 ; P=0.01)$ non-HDL cholesterol concentrations (Table 3). Overall, the models followed a linear trend, with no indication of nonlinear associations (data not shown).

Replacing 5\% of energy from carbohydrates with the same amount of energy from total fats was more strongly associated with higher HDL cholesterol concentrations in females $(0.84 \mathrm{mg} / \mathrm{dL}, 95 \% \mathrm{CI}: 0.46,1.21)$ than in males $(0.44 \mathrm{mg} / \mathrm{dL}$, 95\% CI: 0.07, 0.82; $P$-interaction $=0.05$ ) (Table 4). No statistically significant associations between the replacement of carbohydrates with total fats and non-HDL cholesterol concentrations were observed either in males or females, although there was an indication for a statistically significant interaction by sex $(P$-interaction $=0.01)$. A statistically significant interaction by sex was observed for the association of replacing carbohydrates with MUFAs and non-HDL cholesterol, such that a statistically significant inverse association was found in males and no significant association in females $(P$-interaction $=0.002)$. No other statistically significant interactions by sex were observed. Findings for HDL cholesterol were comparable with the $\mathrm{HDL} / \mathrm{TC}$ ratio where HDL cholesterol was expressed as a percentage of TC (Supplemental Table 2 and Supplemental Figure 1).

SLMAs yielded similar results as in the virtual IPD DataSHIELD analyses (Figure 1 and Supplemental Figures 14 and Supplemental Table 3). For example, replacing $5 \%$ of energy from carbohydrates with total fats in model 2 was statistically significantly associated with $0.63 \mathrm{mg} / \mathrm{dL}$ (95\% CI: $0.35,0.90 ; P$ value for heterogeneity $=0.26$ ) higher $\mathrm{HDL}$ cholesterol in the SLMA, and $0.67 \mathrm{mg} / \mathrm{dL}$ (95\% CI: 0.40, 0.94) higher HDL cholesterol in the virtual IPD analysis. Substantial heterogeneity was observed in the fully adjusted model for the replacement of $5 \%$ of energy from carbohydrates with SFAs and HDL cholesterol in males $\left(I^{2}=66.7 \%, P<0.01\right)$ and non-HDL cholesterol in females $\left(I^{2}=54.2 \%, P=0.04\right)$ (Supplemental Table 3).

Figure 2 shows associations between the (5\% of energy) replacement of carbohydrates with total fats and different types of fats and HDL cholesterol and non-HDL cholesterol stratified by age groups. Positive associations between replacing carbohydrates with total fats and HDL cholesterol concentrations were most pronounced in the middle age groups, e.g. between 41 and 50 y $(1.23 \mathrm{mg} / \mathrm{dL}$ per $5 \%$ energy, $95 \% \mathrm{CI}$ : $0.50,1.97)$, as well as between 51 and $60 \mathrm{y}(0.94 \mathrm{mg} / \mathrm{dL}$ per $5 \%$ energy, 95\% CI: $0.13,1.75)$. Positive associations between the replacement of carbohydrates with SFA and non-HDL cholesterol concentrations were most pronounced between 41 and 50 y $(10.01 \mathrm{mg} / \mathrm{dL}$ per $5 \%$ energy, $95 \%$ CI: $3.91,16.11)$. No statistically significant interactions of the different types of fat with age on either HDL cholesterol or non-HDL cholesterol concentrations were observed (all $P$ values for interaction $>0.05)$. Age-stratified findings for the HDL cholesterol/TC ratio were comparable to those for HDL cholesterol (Supplemental Table 4). The corresponding SLMAs for HDL cholesterol, non-HDL cholesterol, and HDL cholesterol/TC ratio showed similar findings in the age-stratified analysis (Supplemental Table 5). Substantial heterogeneity was observed for the associations between the replacement of carbohydrates with MUFA $\left(I^{2}=62.8 \%, P=0.03\right)$ and PUFA $\left(I^{2}=63.3 \%, P=0.04\right)$, and HDL cholesterol concentrations in the age groups $\geq 60 \mathrm{y}$ and $41-50 \mathrm{y}$, respectively. Substantial heterogeneity was also observed for the associations between the replacement of carbohydrates with total fats $\left(I^{2}=69.9 \%, P=0.02\right)$, MUFA $\left(I^{2}=74.8 \%\right.$, $P<0.01)$, and PUFA $\left(I^{2}=68.8 \%, P=0.02\right)$ and non-HDL 
TABLE 4 Sex-stratified associations between replacement of 5\% of energy from carbohydrates with total fats or types of fats and HDL cholesterol and non-HDL cholesterol among adolescents and adults from 8 European studies ${ }^{1}$

\begin{tabular}{|c|c|c|c|c|}
\hline Type of fat & $\begin{array}{c}\text { HDL-C } \\
\beta(95 \% \mathrm{CI})\end{array}$ & $P$ value & $\begin{array}{c}\text { Non-HDL-C } \\
\beta(95 \% \mathrm{CI})\end{array}$ & $P$ value \\
\hline \multicolumn{5}{|l|}{ Total fats } \\
\hline Males $^{2}(n=2697)$ & $0.44(0.07,0.82)^{*}$ & 0.02 & $-0.27(-1.40,0.85)$ & 0.63 \\
\hline Females $(n=3197)$ & $0.84(0.46,1.21)^{*}$ & $<0.0001$ & $-0.12(-1.08,0.83)$ & 0.80 \\
\hline$P$-interaction by sex & 0.05 & & 0.01 & \\
\hline \multicolumn{5}{|l|}{ SFA } \\
\hline Males $^{2}(n=2697)$ & $0.68(-0.30,1.66)$ & 0.18 & $3.73(0.83,6.63)^{*}$ & 0.01 \\
\hline Females $(n=3197)$ & $0.43(-0.51,1.37)$ & 0.37 & $0.63(-1.77,3.02)$ & 0.61 \\
\hline$P$-interaction by sex & 0.59 & & 0.06 & \\
\hline \multicolumn{5}{|l|}{ MUFA } \\
\hline Males $^{2}(n=2697)$ & $0.67(-0.25,1.59)$ & 0.16 & $-3.03(-5.76,-0.30)^{*}$ & 0.03 \\
\hline Females $(n=3197)$ & $1.16(0.34,1.98)^{*}$ & 0.006 & $0.84(-1.24,2.92)$ & 0.43 \\
\hline$P$-interaction by sex & 0.16 & & 0.002 & \\
\hline \multicolumn{5}{|l|}{ PUFA } \\
\hline Males $^{2}(n=2697)$ & $-0.49(-2.17,1.18)$ & 0.56 & $-2.11(-7.09,2.87)$ & 0.41 \\
\hline Females $(n=3197)$ & $-0.02(-1.54,1.52)$ & 0.43 & $-4.08(-7.95,-0.21)^{*}$ & 0.04 \\
\hline$P$-interaction by sex & 0.21 & & 0.38 & \\
\hline
\end{tabular}

${ }^{1}$ Data are $\beta$-coefficients, upper and lower $95 \% \mathrm{Cls}$. Values of HDL cholesterol and non-HDL cholesterol are expressed in $\mathrm{mg} / \mathrm{dL}$ and total fat, SFA, MUFA, and PUFA intakes as $5 \%$ energy. General linear regression models were used. Model 2 was adjusted for alcohol (yes, no, and continuously in $\mathrm{g} / \mathrm{d}$ ), protein intake, $5 \%$ energy (continuously), total energy intake ( $\mathrm{kcal} / \mathrm{d})$, for age (y), sex, smoking status (never/former, current), BMI ( $\mathrm{kg} / \mathrm{m}^{2}$ ), and study source (EPIC substudy, ActivE, BVS II, DONALD, Pizarra, NESCaV, GINIplus and LISA, INGI-FVG). ${ }^{*} P<0.05$. BVS II, Bavarian Food Consumption Survey II; DONALD, DOrtmund Nutritional and Anthropometric Longitudinally Designed Study; EPIC, European Prospective Investigation into Cancer and Nutrition; GINIplus, German Infant Study on the Influence of Nutrition Intervention plus environmental and genetic influences on allergy development; INGI-FVG, Italian Network of Genetic Isolates-Friuli Venezia Giulia; LISA, Influence of Life-style related factors on the development of the Immune System and Allergies in East and West Germany; GINIplus and LISA are 2 German birth cohorts whose harmonized data were pooled to increase statistical power; NESCaV, Nutrition, Environment, and Cardiovascular Health.

${ }^{2}$ ActivE study excluded in all datasets for males.

cholesterol concentrations in the age group between 31 and 40 y (Supplemental Table 5).

\section{Discussion}

In this large federated cross-sectional analysis of 8 observational studies, we found that the isocaloric replacement of carbohydrates with total fats or MUFAs was positively associated with HDL cholesterol, whereas the replacement of carbohydrates with SFAs was positively associated with non-HDL cholesterol concentrations. The replacement of carbohydrates with PUFAs was inversely associated with nonHDL cholesterol concentrations. Although most associations were similar and in the same direction in males and females, the replacement of carbohydrates with MUFAs was inversely associated with non-HDL cholesterol in males but not in females. We observed no statistically significant interaction by age, although estimates varied across age groups.

In agreement with our findings, there is convincing evidence from randomized trials that the replacement of carbohydrates with total fat or MUFAs increases HDL cholesterol in adults $(15,16,44,45)$. For example, a meta-analysis of 395 published dietary intervention studies conducted under controlled conditions with diets persisting $\geq 2 \mathrm{wk}$ (so-called metabolic ward studies) found that isocaloric increases in MUFA (replacing carbohydrates) increased HDL cholesterol concentrations (45).

It is well-known that a higher intake of SFAs increases LDL cholesterol concentrations, which is considered a major risk factor for CVDs $(46,47)$. The replacement of carbohydrates with SFAs has been consistently associated with higher LDL cholesterol in randomized trials $(15,16,48)$ but not in observational studies (26). However, to our knowledge, no intervention or observational studies relating the isocaloric replacement of carbohydrates with SFAs to non-HDL cholesterol concentrations are currently available.

Literature addressing non-HDL cholesterol in the context of replacing dietary carbohydrates with PUFAs or MUFAs is scarce, whereas results on LDL cholesterol from existing intervention (14-16, 45) and observational studies (26) are conflicting. For example, a randomized, 3-period, crossover feeding study observed that the partial substitution of carbohydrates with unsaturated fats (mainly MUFAs) showed no effects on LDL cholesterol concentrations (14), whereas a meta-analysis of 27 trials (16) and a large systematic review of 84 trials (15) showed that the isocaloric substitution of total carbohydrates with MUFAs or PUFAs significantly decreased LDL cholesterol concentrations. In addition, a meta-analysis of 395 published metabolic ward studies found that isocaloric increases in PUFA intake (replacing carbohydrates) decreased LDL cholesterol, whereas MUFAs had no significant effect on LDL cholesterol (45). Differences in results may be partly explained by studyspecific differences in the n-6/n-3 PUFA ratio, since $n-6$ versus n-3 PUFAs may exert differential effects on lipid profiles (26, 46).

Isocaloric macronutrient exchange models should be interpreted cautiously, as any observed association may be attributed to either the macronutrient of interest (in our case, types of fat) or to the substituted macronutrient. Similar to other studies (12), we chose carbohydrates as a reference macronutrient for our isocaloric exchange models. We conducted additional 

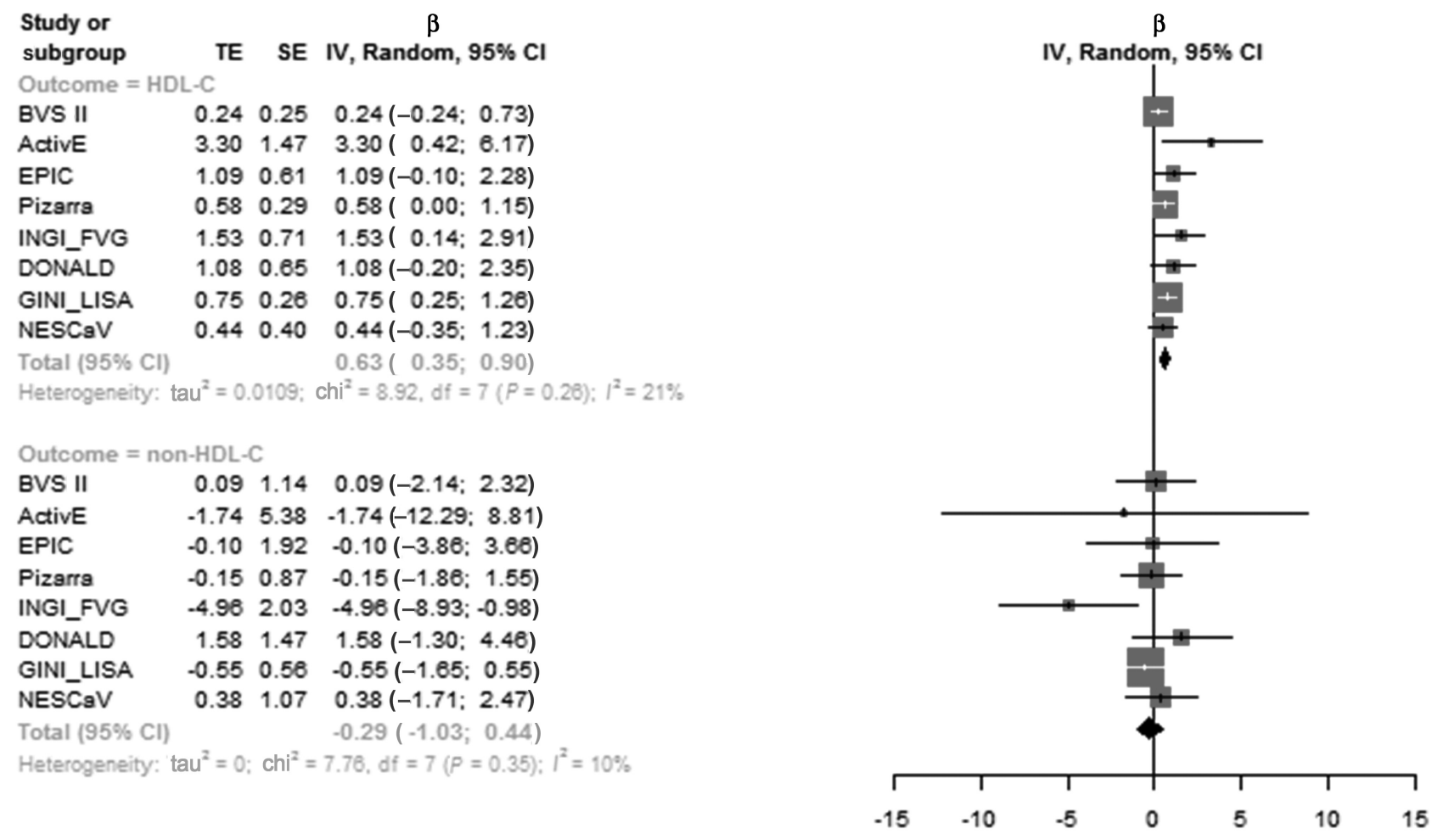

FIGURE 1 Forest plot of random-effects study-level meta-analysis for the association between lipoprotein profiles and percentage of $5 \%$ of energy intake from total fats in replacement of carbohydrates among adolescents and adults from 8 European studies. Values are $\beta$-coefficients, upper and lower $95 \% \mathrm{Cls}$ for all the participants $(n=5919)$. HDL cholesterol and non-HDL cholesterol were expressed in $\mathrm{mg} / \mathrm{dL}$ and total fat intake was expressed as $5 \%$ energy. Model 2 was adjusted for alcohol (yes, no, and continuously in g/d), protein intake, $5 \%$ energy (continuously), total energy intake (kcal/d), for age (y), sex, smoking status (never/former, current), BMI $\left(\mathrm{kg} / \mathrm{m}^{2}\right)$, and study source. The shaded circles represent the point estimate for each individual study, and the horizontal line extending from each square represents the upper and lower limits of the $95 \% \mathrm{Cl}$. The size of the shaded square indicates the relative weight of the study in the meta-analysis. The diamonds represent the overall $\beta$-coefficient of the studies. BVS II, Bavarian Food Consumption Survey II; DONALD, DOrtmund Nutritional and Anthropometric Longitudinally Designed Study; EPIC, European Prospective Investigation into Cancer and Nutrition; GINI, German Infant Study on the Influence of Nutrition Intervention; INGIFVG, Italian Network of Genetic Isolates-Friuli Venezia Giulia; IV, interval variable; LISA, Influence of Life-style related factors on the development of the Immune System and Allergies in East and West Germany; GINIplus and LISA are 2 German birth cohorts whose harmonized data were pooled to increase statistical power; NESCaV, Nutrition, Environment, and Cardiovascular Health; TE, estimated treatment effect.

substitution models in which fats were replaced at the expense of protein intake (instead of carbohydrates) and similar results were found, further supporting that our observations can largely be attributed to fat intake. Most studies in the present analysis had median carbohydrate intakes $<50 \%$, which is lower than the recommended intake by many European nutrition societies (49-52). To avoid unhealthy weight gain, the German guidelines (49) recommend limiting total fat intake to $<30 \%$ of total energy intake (from age $15 \mathrm{y}, 30-35 \%$ between 4 and $15 \mathrm{y}$ ), whilst the Belgian (51), Spanish (52), and Italian (53) guidelines recommend limiting total fat intake $\leq 35 \%$ of total energy intake. However, there is an ongoing debate on limiting the intake of total fats to $<30 \%$ of the total energy intake as previous studies suggest that diets with a higher fat intake are not associated with higher CVD or mortality risk(40). In addition, in terms of unhealthy weight gain, total calorie intake rather than macronutrient composition is the determinant, which underlines the special importance of the isocaloric replacement of macronutrients.

A number of experimental studies in animal models aimed to elucidate the mechanisms by which different types of fatty acids modulate circulating cholesterol concentrations (54-59). Resultant plausible mechanisms that could explain how dietary fats affect circulating LDL cholesterol concentrations include alterations in LDL cholesterol receptor activity, LDL cholesterol receptor protein concentrations, and mRNA abundance (5558); whilst SFAs markedly decrease the LDL cholesterol receptor activity and protein and mRNA concentrations (59), PUFAs upregulated them (55). Furthermore, (n-6) PUFA reduces circulating cholesterol by upregulating the LDL cholesterol receptor and increasing the activity of cholesterol $7 \alpha$-hydroxylase (CYP7) - the initial and rate-limiting enzyme in the conversion of cholesterol to bile acids (60). In human studies, key components of cholesterol metabolism are the cholesterol efflux (a measure of HDL cholesterol functionality), and proprotein convertase subtilisin-kexin type 9 (PCSK9) concentrations, a protein involved in the degradation of LDL cholesterol receptors (60). A randomized trial has shown that a higher intake of PUFAs reduces PCSK9 concentrations (61), which could be another mechanism that might explain why PUFAs exert lipoprotein benefits. However, to our knowledge there are no experimental studies examining specifically biological mechanisms for the effects of replacing carbohydrates with types of fat on HDL or non-HDL concentrations.

A major strength of this study is that it used federated data from large studies conducted in several European countries 


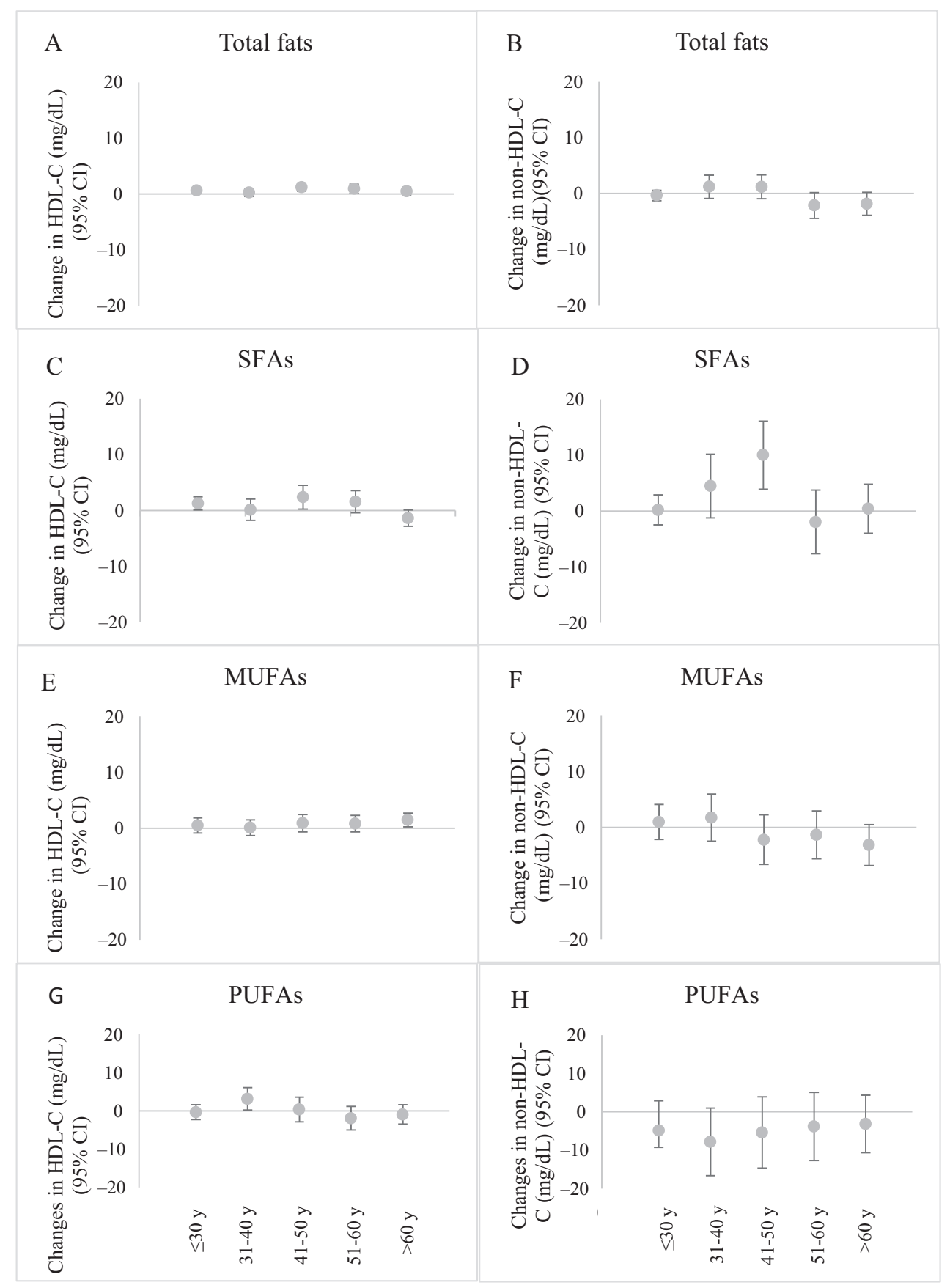

FIGURE 2 Age-stratified analyses on the association between replacement of $5 \%$ of energy from carbohydrates with total fats (A and B), SFAs (C and D), MUFAs (E and F), or PUFAs (G and H) and HDL cholesterol and non-HDL cholesterol among adolescents and adults from 8 European studies. Values are $\beta$-coefficients, upper and lower $95 \% \mathrm{Cls}$ for all the participants $(n=5919)$. HDL cholesterol and non-HDL cholesterol were expressed in $\mathrm{mg} / \mathrm{dL}$ and total fat, SFA, MUFA, and PUFA intakes were expressed as $5 \%$ energy. The circles represent the point estimate for each age group, and the horizontal line extending from each circle represents the upper and lower limits of the $95 \% \mathrm{Cl}$. Model 2 was adjusted for alcohol (yes, no, and continuously in $\mathrm{g} / \mathrm{d}$ ), protein intake, $5 \%$ energy (continuously), total energy intake (kcal/d), for age (y), sex, smoking status (never/former, current), BMI $\left(\mathrm{kg} / \mathrm{m}^{2}\right)$, and study source. Included studies for age category $\leq 30$ y (BVS II, Pizarra, NESCaV, INGI-FVG, GINIplus/LISA, and DONALD); 31-40 and 41-50 years (BVS II, Pizarra, INGI-FVG, and NESCaV); 51-60 and >60 y (BVS II, EPIC substudy, Pizarra, INGI-FVG, and NESCaV); age categories: $\leq 30$ y $(n=2758) ; 31-40$ y $(n=561) ; 41-50$ y $(n=603) ; 51-60$ y $(n=761)$, and $>60$ y $(n=1,141)$. No significant interactions between fats and age were found. BVS II, Bavarian Food Consumption Survey II; DONALD, DOrtmund Nutritional and Anthropometric Longitudinally Designed Study; EPIC, European Prospective Investigation into Cancer and Nutrition; GINIplus, German Infant Study on the Influence of Nutrition Intervention plus environmental and genetic influences on allergy development; INGI-FVG, Italian Network of Genetic Isolates-Friuli Venezia Giulia; LISA, Influence of Life-style related factors on the development of the Immune System and Allergies in East and West Germany; GINIplus and LISA are 2 German birth cohorts whose harmonized data were pooled to increase statistical power; NESCaV, Nutrition, Environment, and Cardiovascular Health 
covering the South and Central Europe, as well as including broad age ranges, showing consistent results across the diverse studies. Another strength is that a priori FAIRyfied harmonization of data before individual-level and study-level metaanalyses were carried out. In addition, the remote federated analysis approach through DataSHIELD allowed us to perform both virtual IPD and study-level meta-analyses without the need to physically pool or share individual-level data, and hence substantially reduced the governance burdens and ethicolegal challenges. Similar effect estimates were observed between the virtually pooled analysis of individual-level data and study-level meta-analyses; the latter though provided, as expected, larger CIs, sometimes losing the statistical significance observed in the virtual IPD analyses. However, by using both virtual IPD GLM analyses and study-level meta-analyses, we demonstrated that there are no serious flaws in the analytic assumption that could disturb either approach: in particular, no serious heterogeneity in the underlying etiological models. The implementation of DataSHIELD in DASH-IN made it possible to perform individual-level analysis. Collection of data via this type of solution may stimulate research on existing data.

Our study has several limitations. First, given the crosssectional nature of our analyses, we can neither confirm the temporal relation between the substitution of carbohydrates for fats and the lipoprotein profiles in our study population nor infer causality. Second, we included 8 studies from 4 European countries among the observational studies identified within the ENPADASI Consortium. Therefore, although participants were recruited from the general population, our studies may not be representative of the European population. Third, residual confounding cannot be ruled out, since not all the studies had potentially important confounding variables such as education, physical activity, and waist circumference available. Fourth, small studies had to be left out in stratified analysis by age and sex due to the risk of potentially disclosive results, which lowered statistical power and hence reduced the chance of detecting a true effect. Fifth, an increased risk of making a Type I error could not be ruled out, especially since we tested multiple outcomes in our exploratory analysis. However, we did not find substantial differences with the level of significance after applying a conservative Bonferroni correction for 12 independent tests ( 3 outcomes, 4 exposures) although the associations between the isocaloric replacement of carbohydrates with SFA or PUFA with higher and lower non-HDL cholesterol concentrations, respectively, were no longer significant after Bonferroni correction for 12 tests $(P$ value $>0.004)$. Sixth, it is known that the effects of replacing carbohydrates may depend in part on the quality of the carbohydrates, however, the quality of carbohydrates was not taken into account, e.g. by considering glycemic index $(41,47)$. In addition, we did not assess differences in the $n-6 / n-3$ PUFA ratio or differences in the food sources of the considered nutrients, e.g. animalderived MUFA versus plant-derived MUFA, which may have exerted differential effects on lipid profiles. Seventh, random measurement error cannot be ruled out from having diluted real associations between nutrients and lipoprotein profiles. One potential source of random measurement error may reside in the methods used for the assessment of dietary macronutrients intake, which was obtained from self-reported FFQs, food records, or 24-h recall as well as the methods and medium used to measure lipoproteins (plasma, which was used in the EPIC substudy versus serum, which was used in all other studies). However, from the forest plots we did not observe substantial heterogeneity among studies for most associations (substantial heterogeneity was only observed in a few associations after stratification by sex or age), meaning that we largely did not find differences between studies with different dietary collection methods, lipoprotein measurement methods, nor studies using plasma versus serum as an analysis medium nor differences between studies located in the South or Central Europe. Whilst it is true that center-specific effects could not be fully elucidated, we adjusted for study source, which partly accounted for center-specific effects. Eighth, data on smoking and BMI were missing for only a few participants. However, we used simple imputations for missing values in 2 covariables, namely BMI and smoking status, to minimize the loss of statistical power, since multiple imputation was not yet available in DataSHIELD version 5.0.0 and the relative simplicity of the underlying data structure was such that the approach to simple imputation was intuitive.

In conclusion, the findings from this large cross-sectional federated analysis of 8 European observational studies suggest that in adolescents and adults, replacing dietary carbohydrates with total fats and MUFAs is related to higher HDL cholesterol concentrations. Our findings also suggest that replacing dietary carbohydrates with either MUFAs or PUFAs is related to lower non-HDL cholesterol, whereas replacing dietary carbohydrates with SFAs is associated with higher non-HDL cholesterol concentrations. The findings on non-HDL cholesterol warrant confirmation by future studies. The consumption of fats in place of carbohydrates showed beneficial effects when fats were consumed in the form of MUFAs or PUFAs but not SFAs. Thus, our findings support global dietary guidelines (62) regarding the detrimental effects of saturated fat intake, although - as has also been indicated in previous studies $(40,63,64)-$ the intake of total fats showed no detrimental effects in the blood lipoprotein profiles. Federated analysis on data is possible and can answer research questions without sharing individual data.

\section{Acknowledgments}

The authors' contributions were as follows- $\mathrm{KN}, \mathrm{MP}$, and TP: designed the research; KN, and MP: conducted the research; SJ, HB, MS-M, MS, CH, JL, CK, UN, JB, SB, CL, CY, PG, AR, GR$\mathrm{M}, \mathrm{AFD}, \mathrm{DA}$, and $\mathrm{PB}$ : provided essential reagents or materials; MP: analyzed data and wrote the manuscript; and $\mathrm{KN}$ and TP: had primary responsibility for final content; and all authors: read and approved the final manuscript.

\section{References}

1. Cardiovascular disease in Europe 2016: an epidemiological update. Eur Heart J 2016;37:3182-3.

2. Millan J, Pinto X, Munoz A, Zuniga M, Rubies-Prat J, Pallardo LF, Masana L, Mangas A, Hernandez-Mijares A, Gonzalez-Santos P, et al. Lipoprotein ratios: physiological significance and clinical usefulness in cardiovascular prevention. Vascular Health and Risk Management 2009;5:757-65.

3. Barbalho SM, Tofano RJ, de Oliveira MB, Quesada KR, Barion MR, Akuri MC, Oshiiwa M, Bechara MD. HDL-C and non-HDL-C levels are associated with anthropometric and biochemical parameters. Jornal Vascular Brasileiro 2019;18:e20180109.

4. Reiner Z, Catapano AL, De Backer G, Graham I, Taskinen MR, Wiklund O, Agewall S, Alegria E, Chapman MJ, Durrington P, et al.ESC/EAS Guidelines for the management of dyslipidaemias: the Task Force for the management of dyslipidaemias of the European Society of Cardiology (ESC) and the European Atherosclerosis Society (EAS). Eur Heart J 2011;32:1769-818. 
5. Sniderman AD, Williams K, Contois JH, Monroe HM, McQueen MJ, de Graaf J, Furberg CD. A meta-analysis of low-density lipoprotein cholesterol, non-high-density lipoprotein cholesterol, and apolipoprotein B as markers of cardiovascular risk. Circulation Cardiovascular Quality and Outcomes 2011;4:337-45.

6. Carr SS, Hooper AJ, Sullivan DR, Burnett JR. Non-HDL-cholesterol and apolipoprotein B compared with LDL-cholesterol in atherosclerotic cardiovascular disease risk assessment. Pathology 2019;51:148-54.

7. Sathiyakumar V, Park J, Quispe R, Elshazly MB, Michos ED, Banach M, Toth PP, Whelton SP, Blumenthal RS, Jones SR, et al. Impact of novel low-density lipoprotein-cholesterol assessment on the utility of secondary non-high-density lipoprotein-C and apolipoprotein B targets in selected worldwide dyslipidemia guidelines. Circulation 2018;138:244-54.

8. Martin SS, Blaha MJ, Elshazly MB, Brinton EA, Toth PP, McEvoy JW, Joshi PH, Kulkarni KR, Mize PD, Kwiterovich PO, et al. Friedewaldestimated versus directly measured low-density lipoprotein cholesterol and treatment implications. J Am Coll Cardiol 2013;62:732-9.

9. Meier T, Gräfe K, Senn F, Sur P, Stangl GI, Dawczynski C, März W, Kleber ME, Lorkowski S. Cardiovascular mortality attributable to dietary risk factors in 51 countries in the WHO European Region from 1990 to 2016: a systematic analysis of the Global Burden of Disease Study. Eur J Epidemiol 2019;34:37-55.

10. Miller ER, 3rd, Erlinger TP, Appel LJ. The effects of macronutrients on blood pressure and lipids: an overview of the DASH and OmniHeart trials. Curr Atheroscler Rep 2006;8:460-5.

11. Flock MR, Fleming JA, Kris-Etherton PM. Macronutrient replacement options for saturated fat: effects on cardiovascular health. Curr Opin Lipidol 2014;25:67-74.

12. Hu FB, Stampfer MJ, Manson JE, Rimm E, Colditz GA, Speizer FE, Hennekens CH, Willett WC. Dietary protein and risk of ischemic heart disease in women. Am J Clin Nutr 1999;70:221-7.

13. Mente A, Dehghan M, Rangarajan S, McQueen M, Dagenais G, Wielgosz A, Lear S, Li W, Chen H, Yi S, et al. Association of dietary nutrients with blood lipids and blood pressure in 18 countries: a crosssectional analysis from the PURE study. Lancet Diabetes Endocrinol 2017;5(10):774-87.

14. Appel LJ, Sacks FM, Carey VJ, Obarzanek E, Swain JF, Miller ER, 3rd, Conlin PR, Erlinger TP, Rosner BA, Laranjo NM, et al. Effects of protein, monounsaturated fat, and carbohydrate intake on blood pressure and serum lipids: results of the OmniHeart randomized trial. JAMA 2005;294:2455-64.

15. Mensink RP. Effects of Saturated Fatty Acids on Serum Lipids and Lipoproteins: A Systematic Review and Regression Analysis. Geneva: World Health Organization; 2016.

16. Mensink RP, Katan MB. Effect of dietary fatty acids on serum lipids and lipoproteins. A meta-analysis of 27 trials. Arteriosclerosis and Thrombosis: A Journal of Vascular Biology 1992;12:911-9.

17. Schwingshackl L, Hoffmann G. Comparison of effects of long-term low-fat vs high-fat diets on blood lipid levels in overweight or obese patients: a systematic review and meta-analysis. Journal of the Academy of Nutrition and Dietetics 2013;113:1640-61.

18. Pinart M, Nimptsch K, Bouwman J, Dragsted LO, Yang C, De Cock N, Lachat C, Perozzi G, Canali R, Lombardo R, et al. Joint data analysis in nutritional epidemiology: identification of observational studies and minimal requirements. J Nutr 2018;148:285-97.

19. Gaye A, Marcon Y, Isaeva J, LaFlamme P, Turner A, Jones EM, Minion J, Boyd AW, Newby CJ, Nuotio ML, et al. DataSHIELD: taking the analysis to the data, not the data to the analysis. Int J Epidemiol 2014;43:1929-44.

20. Wilson RC, Butters OW, Avraam D, Baker J, Tedds JA, Turner A, Murtagh M, Burton PR. DataSHIELD - new directions and dimensions. Data Science Journal 2017;16:1-21.

21. Alkerwi A, Guillaume M, Zannad F, Laufs U, Lair ML. Nutrition, environment and cardiovascular health (NESCAV): protocol of an inter-regional cross-sectional study. BMC Public Health 2010;10: 698.

22. Schaller N, Seiler H, Himmerich S, Karg G, Gedrich K, Wolfram G, Linseisen J. Estimated physical activity in Bavaria, Germany, and its implications for obesity risk: results from the BVS-II Study. The International Journal of Behavioral Nutrition and Physical Activity 2005;2:6.

23. Jaeschke L, Steinbrecher A, Jeran S, Konigorski S, Pischon T. Variability and reliability study of overall physical activity and activity intensity levels using 24 h-accelerometry-assessed data. BMC Public Health 2018;18:530.

24. von Ruesten A, Feller S, Bergmann MM, Boeing H. Diet and risk of chronic diseases: results from the first 8 years of follow-up in the EPICPotsdam study. Eur J Clin Nutr 2013;67:412-9.

25. Buyken AE, Alexy U, Kersting M, Remer T. [The DONALD cohort. An updated overview on 25 years of research based on the Dortmund Nutritional and Anthropometric Longitudinally Designed study]. Bundesgesundheitsblatt Gesundheitsforschung Gesundheitsschutz 2012;55:875-84.

26. Harris CP, Berg A, Berdel D, Bauer CP, Schikowski T, Koletzko S, Heinrich J, Schulz H, Standl M. Association of dietary fatty acids with blood lipids is modified by physical activity in adolescents: results from the GINIplus and LISA Birth Cohort Studies. Nutrients 2018;10(10):1372.

27. Robino A, Bevilacqua L, Pirastu N, Situlin R, Di Lenarda R, Gasparini $\mathrm{P}$, Navarra CO. Polymorphisms in sweet taste genes (TAS1R2 and GLUT2), sweet liking, and dental caries prevalence in an adult Italian population. Genes Nutr 2015;10(5):485.

28. Soriguer F, Almaraz MC, Garcia-Almeida JM, Cardona I, Linares F, Morcillo S, Garcia-Escobar E, Dobarganes MC, Olveira G, Hernando V, et al. Intake and home use of olive oil or mixed oils in relation to healthy lifestyles in a Mediterranean population. Findings from the prospective Pizarra study. Br J Nutr 2010;103:114-22.

29. Harris C, Flexeder C, Thiering E, Buyken A, Berdel D, Koletzko S, Bauer CP, Brüske I, Koletzko B, Standl M. Changes in dietary intake during puberty and their determinants: results from the GINIplus birth cohort study. BMC Public Health 2015;15:1, 841.

30. Kroke A, Klipstein-Grobusch K, Voss S, Möseneder J, Thielecke F, Noack R, Boeing H. Validation of a self-administered food-frequency questionnaire administered in the European Prospective Investigation into Cancer and Nutrition (EPIC) Study: comparison of energy, protein, and macronutrient intakes estimated with the doubly labeled water, urinary nitrogen, and repeated $24-\mathrm{h}$ dietary recall methods. Am J Clin Nutr 1999;70:439-47.

31. Stiegler P, Sausenthaler S, Buyken AE, Rzehak P, Czech D, Linseisen J, Kroke A, Gedrich K, Robertson C, Heinrich J. A new FFQ designed to measure the intake of fatty acids and antioxidants in children. Public Health Nutr 2010;13:38-46.

32. Sauvageot N, Alkerwi A, Adelin A, Guillaume M. Validation of the food frequency questionnaire used to assess the association between dietary habits and cardiovascular risk factors in the NESCAV Study. Journal of Nutrition and Food Sciences 2013;3:208.

33. Schmidt LE, Cox MS, Buzzard IM, Cleary PA. Reproducibility of a comprehensive diet history in the Diabetes Control and Complications Trial. The DCCT Research Group. J Am Diet Assoc 1994;94: 1392-7.

34. Bokhof B, Günther AL, Berg-Beckhoff G, Kroke A, Buyken AE. Validation of protein intake assessed from weighed dietary records against protein estimated from $24 \mathrm{~h}$ urine samples in children, adolescents and young adults participating in the Dortmund Nutritional and Longitudinally Designed (DONALD) Study. Public Health Nutr 2010;13:826-34.

35. Soriguer FJC, González-Romero S, Esteva de Antonio I, García Arnés J, Tinahones Madueño F, Ruiz de Adana MS. Validación de una encuesta nutricional. Nutrición Clínica 1992;12:33-41.

36. Wilkinson MD, Dumontier M, Aalbersberg IJ, Appleton G, Axton M, Baak A, Blomberg N, Boiten JW, da Silva Santos LB, Bourne PE, et al. The FAIR Guiding Principles for scientific data management and stewardship. Scientific Data 2016;3:160018.

37. Jones E, Sheehan N, Masca N, Wallace S, Murtagh M, Burton P. DataSHIELD - shared individual-level analysis without sharing the data: a biostatistical perspective. Norsk Epidemiologi 2012; 21(2): 231-9.

38. Deeks JJ, Higgins JPT, Altman DG (editors). Chapter 10: Analysing data and undertaking meta-analyses. In: Higgins JPT, Thomas J, Chandler J, Cumpston M, Li T, Page MJ, Welch VA (editors). Cochrane Handbook for Systematic Reviews of Interventions version 6.1. Cochrane, 2020.

39. Willett W, Stampfer MJ. Total energy intake: implications for epidemiologic analyses. Am J Epidemiol 1986;124:17-27.

40. Dehghan M, Mente A, Zhang X, Swaminathan S, Li W, Mohan V, Iqbal R, Kumar R, Wentzel-Viljoen E, Rosengren A, et al. Associations of fats and carbohydrate intake with cardiovascular disease and mortality in 
18 countries from five continents (PURE): a prospective cohort study. Lancet North Am Ed 2017;390:2050-62.

41. Jakobsen MU, Dethlefsen C, Joensen AM, Stegger J, Tjonneland A, Schmidt EB, Overvad K. Intake of carbohydrates compared with intake of saturated fatty acids and risk of myocardial infarction: importance of the glycemic index. Am J Clin Nutr 2010;91: 1764-8.

42. Avraam D, Wilson R, Butters O, Burton T, Nicolaides C, Jones E, Boyd A, Burton P. Privacy preserving data visualizations. EPJ Data Science 2021;10:2

43. Matthews GJ, Harel O, Aseltine RH. Privacy protection and aggregate health data: a review of tabular cell suppression methods (not) employed in public health data systems. Health Services and Outcomes Research Methodology 2016;16:258-70.

44. FAO. Fats and Fatty Acids in Human Nutrition. Report of an expert consultation: WHO; 2010.

45. Clarke R, Frost C, Collins R, Appleby P, Peto R. Dietary lipids and blood cholesterol: quantitative meta-analysis of metabolic ward studies. BMJ 1997;314:112-7.

46. Lichtenstein AH. Thematic review series: patient-oriented research. Dietary fat, carbohydrate, and protein: effects on plasma lipoprotein patterns. J Lipid Res 2006;47:1661-7.

47. Siri-Tarino PW, Sun Q, Hu FB, Krauss RM. Saturated fatty acids and risk of coronary heart disease: modulation by replacement nutrients. Curr Atheroscler Rep 2010;12:384-90.

48. Mensink RP, Zock PL, Kester AD, Katan MB. Effects of dietary fatty acids and carbohydrates on the ratio of serum total to HDL cholesterol and on serum lipids and apolipoproteins: a meta-analysis of 60 controlled trials. Am J Clin Nutr 2003;77:1146-55.

49. Deutsche Gesellschaft für Ernährung, Österreichische Gesellschaft für Ernährung, Schweizerische Gesellschaft für Ernährung, Hrsg [Internet]. Available from: https://www.dge.de/wissenschaft/referenzwerte/fett/? $\mathrm{L}=0 ; 2011$.

50. Società Italiana di Nutrizione Umana-SINU 2014. LARN - Livelli di assunzione di riferimento per la popolazione italiana: CARBOIDRATI E FIBRA ALIMENTARE [Internet]. Available from: https://sinu.it/2019 /07/09/carboidrati-e-fibra-alimentare/.

51. Plan National Nutrition Santé (PNNS), une initiative du Ministre des Affaires Sociales et de la Santé Publique [Internet]. Available from: http: //www.fao.org/3/a-as664f.pdf. 2017.

52. Consenso de la Sociedad Española de Nutrición Comunitaria. Objetivos nutricionales para la población española. Revista Española de Nutición Comunitaria 2011;17:178-99.
53. Società Italiana di Nutrizione Umana-SINU 2014. LARN - Livelli di assunzione di riferimento per la popolazione italiana: LIPIDI [Internet]. Available from: https://sinu.it/2019/07/09/lipidi/.

54. Fernandez ML, West KL. Mechanisms by which dietary fatty acids modulate plasma lipids. J Nutr 2005;135:2075-8.

55. Fernandez ML, McNamar DJ. Dietary fat-mediated changes in hepatic apoprotein $\mathrm{B} / \mathrm{E}$ receptor in the guinea pig: effect of polyunsaturated, monounsaturated, and saturated fat. Metabolism 1989;38:1094-102.

56. Fernandez ML, McNamara DJ. Regulation of cholesterol and lipoprotein metabolism in guinea pigs mediated by dietary fat quality and quantity. J Nutr 1991;121:934-43.

57. Fernandez ML, Lin EC, McNamara DJ. Differential effects of saturated fatty acids on low density lipoprotein metabolism in the guinea pig. J Lipid Res 1992;33:1833-42.

58. Fernandez ML, Lin EC, McNamara DJ. Regulation of guinea pig plasma low density lipoprotein kinetics by dietary fat saturation. J Lipid Res 1992;33:97-109.

59. Mustad VA, Ellsworth JL, Cooper AD, Kris-Etherton PM, Etherton TD. Dietary linoleic acid increases and palmitic acid decreases hepatic LDL receptor protein and mRNA abundance in young pigs. J Lipid Res 1996;37:2310-23.

60. Tindall AM, Kris-Etherton PM, Petersen KS. Replacing saturated fats with unsaturated fats from walnuts or vegetable oils lowers atherogenic lipoprotein classes without increasing lipoprotein(a). J Nutr 2020;150:818-25.

61. Bjermo H, Iggman D, Kullberg J, Dahlman I, Johansson L, Persson L, Berglund J, Pulkki K, Basu S, Uusitupa M, et al. Effects of n-6 PUFAs compared with SFAs on liver fat, lipoproteins, and inflammation in abdominal obesity: a randomized controlled trial. Am J Clin Nutr 2012;95:1003-12.

62. WHO. World Health Organization healthy diet fact sheet number 394 [Internet]. Available from: www.who.int/mediacentre/factsheets/fs394/e $\mathrm{n} / ; 2017$.

63. Ramsden CE, Zamora D, Majchrzak-Hong S, Faurot KR, Broste SK, Frantz RP, Davis JM, Ringel A, Suchindran CM, Hibbeln JR. Reevaluation of the traditional diet-heart hypothesis: analysis of recovered data from Minnesota Coronary Experiment (1968-73). BMJ (Clinical Research ed) 2016;353:i1246.

64. Meisinger C, Rospleszcz S, Wintermeyer E, Lorbeer R, Thorand B, Bamberg F, Peters A, Schlett CL, Linseisen J. Isocaloric substitution of dietary carbohydrate intake with fat intake and MRI-determined total volumes of visceral, subcutaneous and hepatic fat content in middleaged adults. Nutrients 2019;11:1151. 